\title{
Postpartum Changes in the Mechanical Responses of the Circular Muscle of Rat Uterus
}

\author{
Takuro OsA and Keiji Maruta \\ Department of Physiology, Yamaguchi University School \\ of Medicine, Ube, 755 Japan
}

\begin{abstract}
The circular muscle strips were isolated from rat uterus $10-60 \mathrm{~h}$ after parturition, and the electrical and mechanical responses were investigated. The muscle strips exhibited a variety of contractile activity ranging from frequent spontaneous contractions generated on an elevated muscle tone to a sustained contracture, when incubated with $\mathrm{Mg}$-free Krebs solution. The muscle tone was lowered, and phasic contractions were abolished when the external $\mathrm{Ca}$ was removed. Muscle tone was also lowered by addition of $1.2 \mathrm{~mm} \mathrm{Mg}, 1 \mathrm{~mm}$ spermidine, or $1 \mathrm{~mm}$ tetracaine. The membrane potential was about $-25 \mathrm{mV}$ in a muscle which exhibited a contracture, and the membrane was hyperpolarized by $20-25 \mathrm{mV}$ by the application of $1.2 \mathrm{~mm} \mathrm{Mg}$ or $1 \mathrm{~mm}$ spermidine. Addition of indomethacin $\left(1.5-4.5 \times 10^{-5} \mathrm{M}\right)$ caused a gradual decrease in muscle tone, and the membrane was hyperpolarized. In view of the above results, it is hypothesized that $\mathrm{Ca}$-influx was increased, for which prostaglandin(s) was probably responsible, in the circular muscle of postpartum rat uterus, thereby elevating the muscle tone in $\mathrm{Mg}$-free solution.
\end{abstract}

Key words: postpartum myometrium, $\mathrm{Mg}$, tetracaine, spermidine, indomethacin.

After parturition the rat uterus returns to its preparturient size in about 4 days. This is accomplished by cellular atrophy and cell destruction. The former occurs mainly in the myometrium as a simple reversal of the hypertrophy induced during pregnancy (MORTON and GoLDSPINK, 1986). Maximum number and size of gap junctions between myometrial cells declined rapidly within a day after delivery (PURI and Garfield, 1982; Saito et al., 1985). The membrane activity of postpartum myometrium has also been a subject of several investigators. The action potential of the circular muscle of near-term rat uterus is composed of spike activity (Osa aned Fujino, 1978; Kawarabayashi and Marshall, 1981; Bengtsson $e t$ al., 1984), and transformed into the plateau potential about $40 \mathrm{~h}$ after the parturition

Received for publication February 18, 1988 
(KishiKaWA, 1981; Maruta et al., 1985a). Thus, the uterine muscle membrane is one of the targets of postpartum hormonal effects. It was found in the preliminary experiment that in the circular muscle excised from the rat about $10-40 \mathrm{~h}$ after parturition, the muscle tone was elevated and spontaneous contractions were very frequent during incubation with $\mathrm{Mg}$-free $\mathrm{Krebs}$ solution. In some preparations, the muscle strip underwent a persistent contracture. This feature strongly contrasted to that observed in the prepartum preparation (OsA and OGaSAWARA, 1983).

To investigate how and why the muscle tone of the postpartum circular muscle was elevated in Mg-free Krebs solution is the main subject of present study. Particular attention was directed to the effects of $\mathrm{Mg}$, tetracaine, and spermidine which are supposed to reduce the Ca-influx (Feinstein, 1965; Hashimoto et al., 1973; Altura and Altura, 1981; Chideckel et al., 1985; Maruta et al., 1985b; Osa and MARUTA, 1986). It is hypothesized that Ca-influx, for which the raised synthesis of prostaglandins is probably responsible, is increased in the circular myometrial tissue of postpartum rat uterus.

\section{METHODS}

Wistar rats weighing $250-300 \mathrm{~g}$ were used. Proestrous rats were housed with males overnight, and Day 1 of pregnancy was the day that sperms were found in the vaginal smear. Delivery usually occurred on Day 22 or Day 23 of pregnancy. The present work was carried out on uteri taken from animals sacrificed between 10 and $60 \mathrm{~h}$ after the delivery of the first newborn. The uterus was cut open along the mesometrium, and the endometrium was removed carefully using jeweler's forceps. Circular and longitudinal muscle strips were dissected with fine scissors from the antimesometrial part of ovarian portion of the uterus.

Microelectrode and tension records were made on muscle strips $1 \mathrm{~mm}$ wide and $5 \mathrm{~mm}$ long by a glass microelectrode filled with $3 \mathrm{M} \mathrm{KCl}$ and a force transducer, respectively, in the partition chamber as described by ABE and Tоміт (1968). For mechanical recording alone, a pair of muscle strips about $0.5 \mathrm{~mm}$ wide and $3 \mathrm{~mm}$ long dissected from the same animal were set up vertically in a recording chamber, and connected to force transducers. The solutions were continuously flowed at a rate of $8 \mathrm{ml} / \mathrm{min}$, and the capacity of the chamber was $2 \mathrm{ml}$. Ag-AgCl electrodes were placed near ends of muscle strips, and electric pulse with $500 \mathrm{~ms}$ duration was applied when necessary. Stimulus intensity was about twice as strong as rheobase. The preparation was equilibrated with warm $\mathrm{Krebs}$ solution $\left(37 \pm 0.5^{\circ} \mathrm{C}, \mathrm{Mg}\right.$-free) for $1-2 \mathrm{~h}$ before the experiment began.

The control solution ( $\mathrm{Mg}$-free Krebs solution) had the following composition (mм): $\mathrm{NaCl} 123.1, \mathrm{NaHCO}_{3}$ 15.5, $\mathrm{KCl} 4.7 . \mathrm{KH}_{2} \mathrm{PO}_{4}$ 1.2, $\mathrm{CaCl}_{2} 2.5$, and glucose 11.5. It was equilibrated with a gas mixture of $95 \% \mathrm{O}_{2}+5 \% \mathrm{CO}_{2}(\mathrm{pH}$ of 7.4). A small amount of $1 \mathrm{M} \mathrm{Mg}$ solution was added to yield a desired concentration. Drugs used were tetracaine (Sigma), spermidine and spermine (Sigma), and glycoletherdiamine-tetraacetic acid (EGTA, Tokyo Kasei) which was titrated with 
tris(hydroxymethyl) aminomethane to be $\mathrm{pH}$ of 7.4. Indomethacin (Sigma) was dissolved in ethanol, after the method described by Sакамото et al. (1987), and added to the bathing solution. The final concentration of ethanol was less than $0.2 \%$. Prostaglandins were the gift of Ono Pharmaceutical Company.

\section{RESULTS}

\section{Postpartum preparations}

Circular muscle strips were obtained from the postpartum rat uteri at periods ranging between 10 and $21 \mathrm{~h}$ after parturition, and incubated with $\mathrm{Mg}$ free Krebs solution (Fig. 1). The contractile activity was full of varieties, exhibiting frequent spontaneous phasic contractions $(\mathrm{A}, \mathrm{B})$ or a sustained contracture
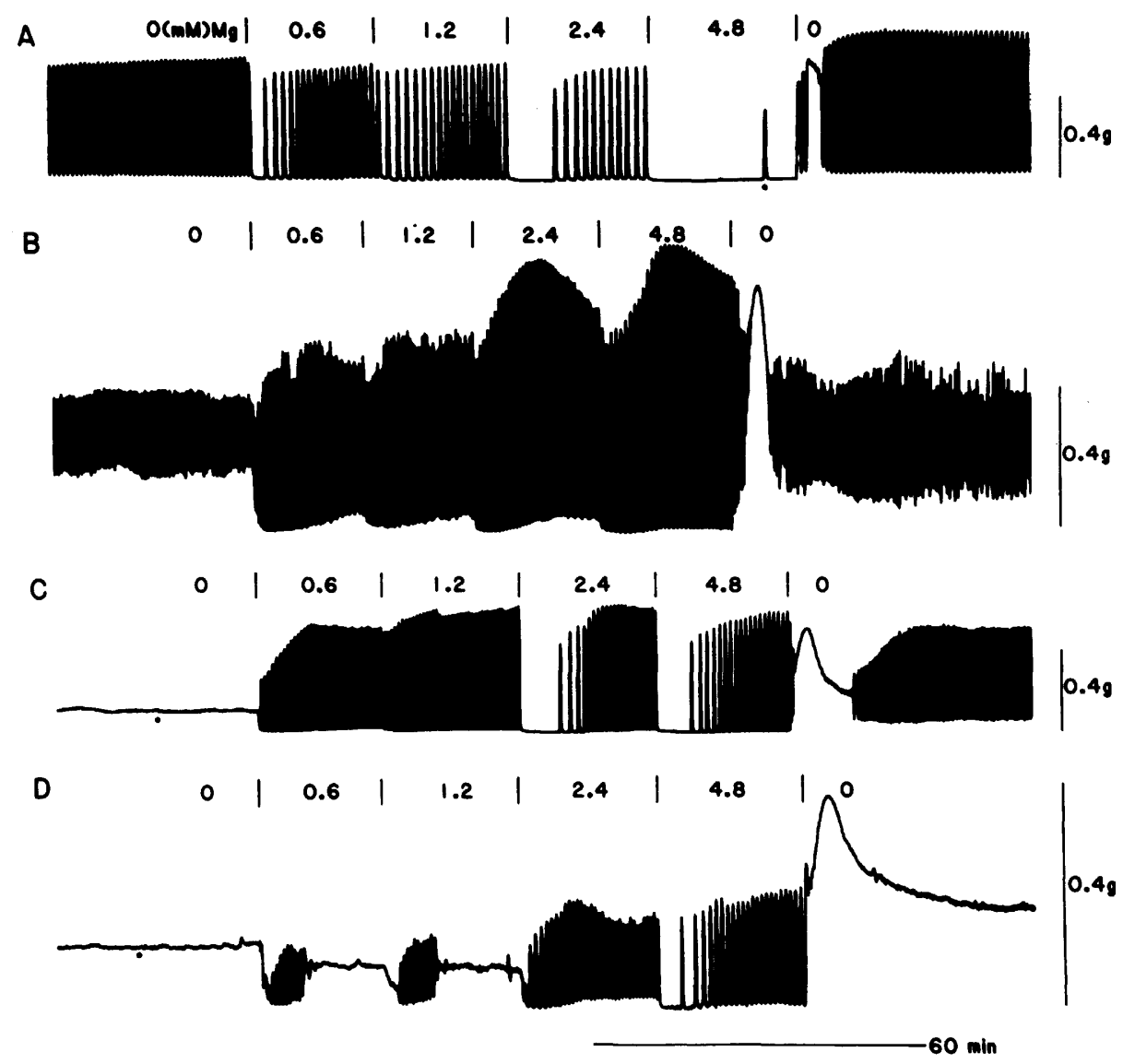

Fig. 1. Effects of raising external $\mathrm{Mg}$ on mechanical activity of circular muscle strips excised from rat uteri 10 (A), 14.5 (B), 16 (C), $21 \mathrm{~h}$ (D) after parturition of the first newborn. $\mathrm{Mg}$ concentrations in $\mathrm{mm}$ are indicated between vertical bars. Dots indicate the electrical stimulation $(500 \mathrm{~ms})$. 
(C, D). Record A shows that increase in external Mg concentrations in steps decreased the frequency and amplitude of phasic contractions dose-dependently, and spontaneous contraction was abolished by $4.8 \mathrm{~mm} \mathrm{Mg}$. The basal muscle tone declined slightly by increasing external $\mathrm{Mg}$ concentrations. The spontaneous activity appeared with greater frequency in the preparation shown in record B. Raising external $\mathrm{Mg}$ concentration $(0.6-4.8 \mathrm{~mm})$ caused a lowering of basal muscle tone, and the amplitude of phasic contractions was hightened. Record $\mathrm{C}$ indicates that the muscle strip was spontaneously inactive and the electrical pulse was incapable of generating a phasic contraction. This contractile feature was proved to be a contracture, because application of $\mathrm{Mg}$ resulted in the depression of muscle tone, and caused a generation of spontaneous phasic contractions. Frequency of spontaneous activity was decreased when $\mathrm{Mg}$ concentration was raised to $4.8 \mathrm{~mm}$. When $\mathrm{Mg}$ was removed, the muscle tension rose slowly then decayed, and phasic contractions of high frequency took place. Effects of external $\mathrm{Mg}$ application were somewhat different in the case of record $\mathrm{D}$. When 0.6 or $1.2 \mathrm{~mm} \mathrm{Mg}$ was applied, the muscle tone declined and phasic contractions were generated, and the muscle strip again underwent a contracture, the level of which was lower than that in the absence of $\mathrm{Mg}$. When 2.4 or $4.8 \mathrm{mM} \mathrm{Mg}$ was applied, the generation of phasic contractions continued. The muscle tension rose slowly and decayed, and a contracture ensued, when $\mathrm{Mg}$ was removed.

Muscle strips were incubated with $\mathrm{Mg}$-free solution containing $0.6 \mathrm{~mm} \mathrm{Ca}$, and effects of raising external $\mathrm{Ca}$ concentration were examined (Fig. 2). In the case of either A or B, muscle strips were spontaneously inactive, and electrical pulses caused a tiny contraction. In the case of record A, raising external Ca (1.2-4.8 mM) caused a generation of spontaneous phasic contractions, and the amplitude increased dose-dependently on the external $\mathrm{Ca}$ concentration. The basal muscle tension was elevated only slightly. In the case of record $\mathrm{B}$, the level of muscle tone was elevated by increasing Ca concentration in steps from 0.6 to $2.4 \mathrm{~mm}$, but the electrical pulses did not evoke a full-size phasic contraction. In the presence of $2.4 \mathrm{~mm} \mathrm{Ca}$, application of $1.2 \mathrm{~mm} \mathrm{Mg}$ caused a lowering of muscle tone, and a generation of spontaneous phasic contractions. When $\mathrm{Mg}$ was removed, phasic contractions of high frequency were induced, and the amplitude was gradually decreased. The amplitude of phasic contractions was augmented by successive application of $4.8 \mathrm{~mm} \mathrm{Ca}$.

High frequency of phasic contractions and contracture of postpartum circular muscle in $\mathrm{Mg}$-free solution suggest a membrane depolarization. Since it was shown that the membrane of smooth muscle was hyperpolarized in low $\mathrm{K}$ solution (CASTEels and KuriYAma, 1965), mechanical effects of reducing external K from 5.9 to $3 \mathrm{mM}$ were examined (Fig. 3). A sustained contracture was transformed into a generation of phasic contractions produced on a lowered muscle tone in $3 \mathrm{~mm} \mathrm{~K}$ solution, and the phasic contractions ensued when $\mathrm{K}$ concentration was restored to $5.9 \mathrm{~mm}$. The second application of $3 \mathrm{~mm} \mathrm{~K}$ solution caused a lowering of the level of maximal relaxation. Spontaneous activity was abolished, and the muscle was 


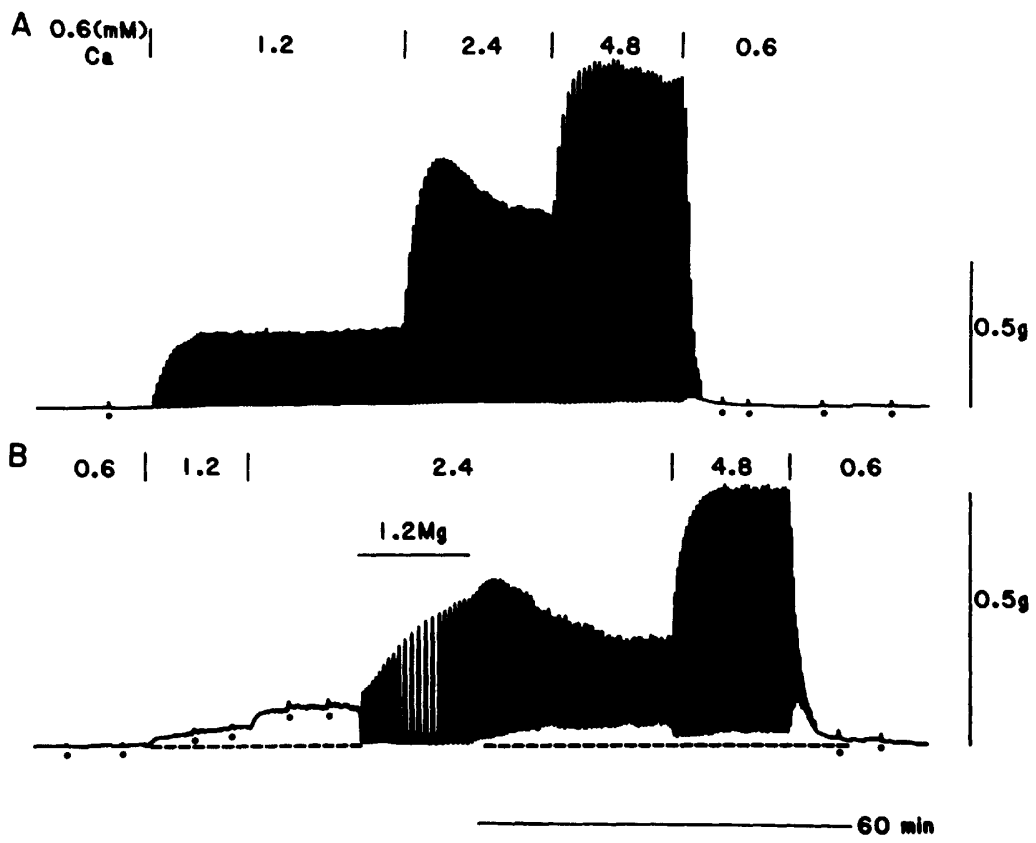

Fig. 2. Contractions of postpartum circular muscle strips illustrating effects of different concentrations of external $\mathrm{Ca}$ added to $\mathrm{Mg}$-free $\mathrm{Krebs}$ solution. $\mathrm{Ca}$ concentrations in $\mathrm{mM}$ are indicated between vertical bars. In record $\mathrm{B}, 1.2 \mathrm{mM} \mathrm{Mg}$ was applied (horizontal bar) in the presence of $2.4 \mathrm{~mm} \mathrm{Ca}$. Dots indicate electrical stimulation. Circular muscle strips were excised from rats 15 (A) and $28 \mathrm{~h}(\mathrm{~B})$ after parturition, respectively.

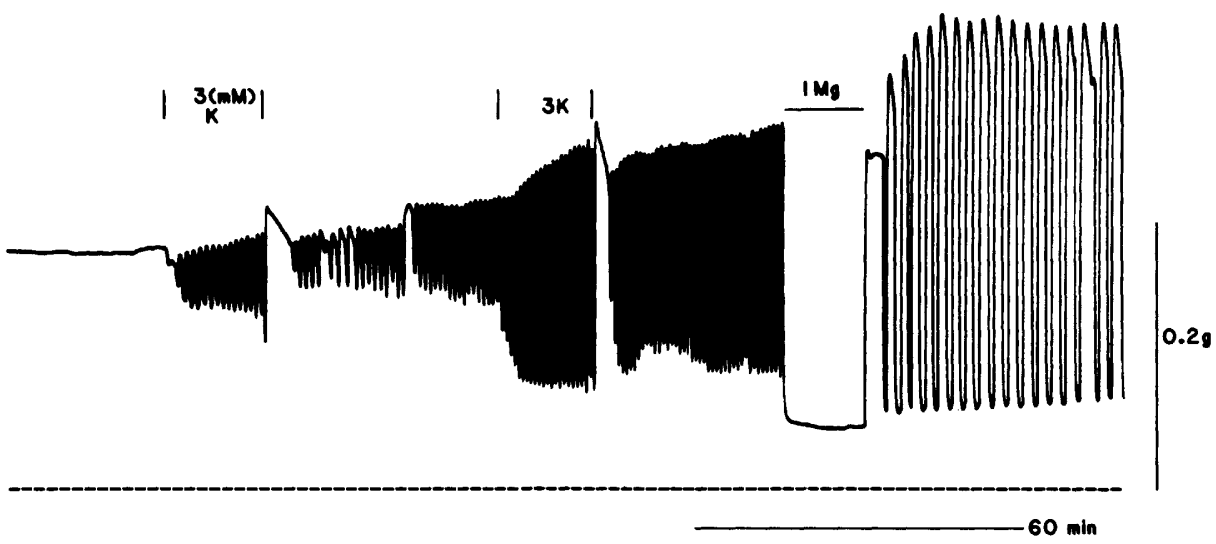

Fig. 3. Contractions of postpartum circular muscle strips in $\mathrm{Mg}$-free Krebs solution illustrating effects of reducing external $\mathrm{K}$ from 5.9 to $3.0 \mathrm{~mm}$ (vertical bars), and addition of $1 \mathrm{~mm} \mathrm{Mg}$ (horizontal bar). Broken lines indicate the slack muscle tension level. Circular muscle strip was excised $46.5 \mathrm{~h}$ after parturition. 


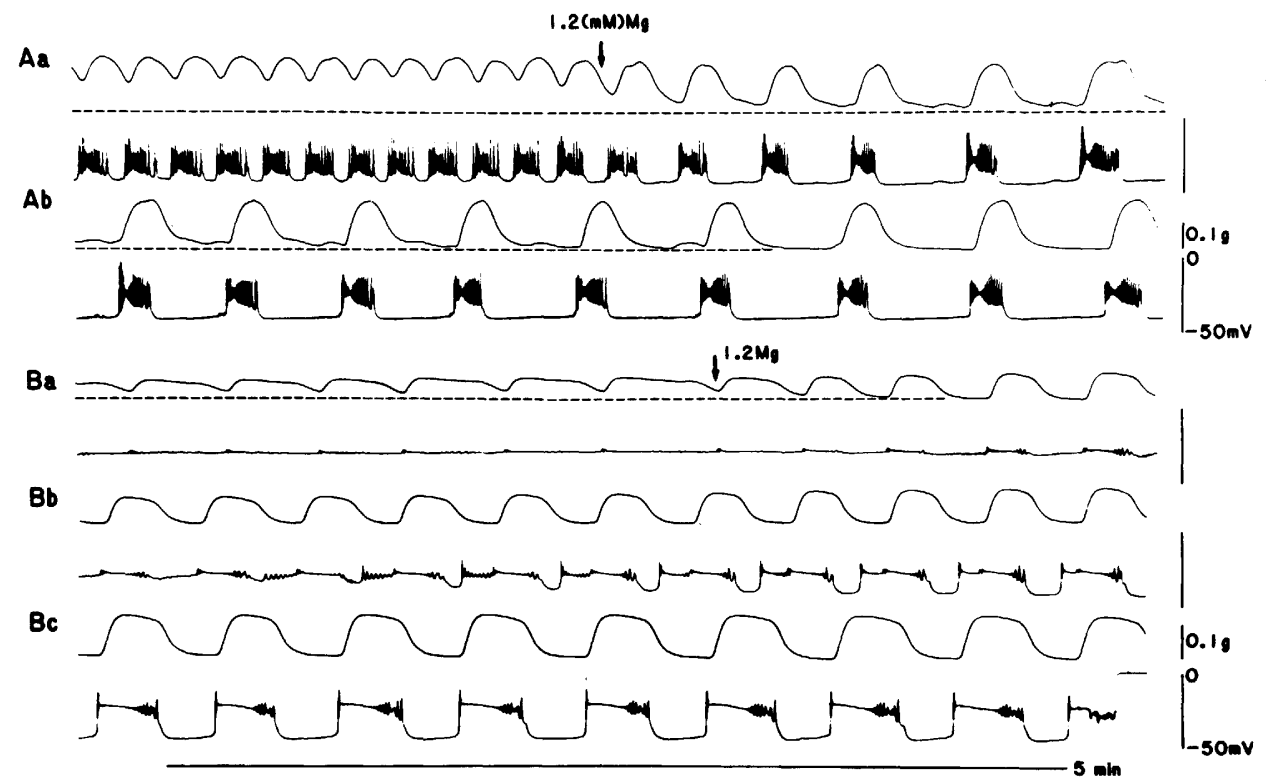

Fig. 4. Membrane activities (lower traces) of postpartum circular muscles of rat uterus illustrating effects of $1.2 \mathrm{~mm} \mathrm{Mg}$. Contractions were simultaneously recorded (upper traces). Muscles were excised 29 (A), $38 \mathrm{~h}$ (B) after parturition and incubated with $\mathrm{Mg}$-free Krebs solution, and $1.2 \mathrm{mM} \mathrm{Mg}$ was applied at the time indicated by arrows. $\mathrm{Ab}$ and $\mathrm{Bb}$ are successive records of $\mathrm{Aa}$ and $\mathrm{Ba}$, respectively. Interval between the end of $\mathrm{Bb}$ and the beginning of $\mathrm{Bc}$ was $4 \mathrm{~min}$.

relaxed when $1 \mathrm{~mm} \mathrm{Mg}$ was added.

The intracellular membrane activity of postpartum circular muscles exposed to $\mathrm{Mg}$-free Krebs solution, and effects of adding $1.2 \mathrm{mM} \mathrm{Mg}$ were examined in the experiment shown in Fig. 4. In the case of record Aa, the membrane activity was composed of periodic bursts of spike potentials, and phasic contractions were generated in a one-to-one manner corresponding to each burst. The membrane was hyperpolarized by $2 \mathrm{mV}$, the amplitude of spike potential was augmented, and interval between action potential was prolonged, when $1.2 \mathrm{mM} \mathrm{Mg}$ was applied. At the steady sate, the amplitude of slow potential increased (Fig. 4Ab). As the frequency of spontaneous activity decreased, the level of maximal relaxation was lowered (Fig. 4Aa). It is probable that in the $\mathrm{Mg}$-free solution the successive contraction occurred before the preceding contraction was completely relaxed. In the case of record $\mathrm{Ba}$, the membrane potential was $-30 \mathrm{mV}$, and action potentials having very small amplitude occurred accompanied with phasic contractions. The membrane was gradually hyperpolarized by the application of $1.2 \mathrm{~mm} \mathrm{Mg}$, and was stabilized at $-46 \mathrm{mV}$ (Fig. $4 \mathrm{Bc}$ ). The amplitude of action potential developed gradually exhibiting complicated shapes (Fig. 4Ba, Bb), and the steady response was the spike potential followed by plateau potential (Fig. $4 \mathrm{Bc}$ ). The level of maximal 
relaxation declined in the presence of $1.2 \mathrm{~mm} \mathrm{Mg}$.

Tetracaine is known as one of the smooth muscle relaxants. Its action is ascribed to the suppression of Ca-influx (Feinstein, 1966; MARUTA and Osa, 1987). Figure 5 demonstrates effects of $\mathrm{Ca}$ removal, and application of $1 \mathrm{~mm}$ tetracaine in the presence of $2.5 \mathrm{~mm} \mathrm{Ca}(\mathrm{Mg}$-free). In record $\mathrm{A}$, the muscle exhibited phasic contractions. Ca omission together with application of $0.5 \mathrm{~mm}$ EGTA caused finally a muscle relaxation following the initial elevation of muscle tension. Application of $1 \mathrm{~mm}$ tetracaine also caused a relaxation. The recovery was very slow. In record B, the muscle exhibited a contracture, and $\mathrm{Ca}$ removal caused a muscle relaxation. The relaxation was rapid. Similarly, $1 \mathrm{~mm}$ tetracaine caused a muscle relaxation. The muscle was rapidly relaxed by $1 \mathrm{~mm} \mathrm{Mg}$, and the extent of relaxation was large.

It has been shown that spermidine or spermine depressed the phasic contraction of rat uterine muscle (НАSHIMOTO et al., 1973; MARUTA et al., 1985b), and tonic contraction of trachealis muscle of guinea pig (CHIDECKEL et al., 1985). Its action is very likely due to the suppression of Ca-influx. Figure 6 demonstrates effects of spermidine and spermine on 2 preparations which exhibited different patterns of contraction in $\mathrm{Mg}$-free Krebs solution. In record $\mathrm{A}$, the level of maximal relaxation was lowered, and the peak of phasic contraction exceeded the previous control by the application of $0.3 \mathrm{~mm}$ spermidine, the feature of which is reminiscent of the effects of $\mathrm{Mg}$ shown in Fig. 1B. Similar effects on the basal muscle tension was caused by $1 \mathrm{~mm}$ spermidine, and the amplitude of phasic contraction was slightly depressed. Later on, the muscle tone tended to elevate and the amplitude of phasic contraction decreased. Spermine $(1 \mathrm{~mm})$ strongly depressed the basal muscle tension, and spontaneous activity was abolished. In record B, the muscle exhibited a contracture, and the muscle tension was progressively increasing. Spermidine depressed the contracture in a dose-dependent manner. When $1 \mathrm{~mm}$ spermine was applied, the muscle underwent a strong relaxation, and phasic contractions having small amplitude were spontaneously generated. The second application of $1 \mathrm{~mm}$ spermidine caused initially a generation of phasic contractions; however, the muscle underwent a contracture again.

Effects of spermidine on the intracellular membrane activity are illustrated in Fig. 7. Periodic bursts of spike potential were the dominant membrane activity, and phasic contractions accompanied in the case of Fig. 7A. When $1 \mathrm{~mm}$ spermidine was applied, the resting membrane potential was not affected, but the frequency of spontaneous activity was decreased (Fig. 7Aa). The level of maximal relaxation slightly declined. The membrane was depolarized, and spike potentials were frequently generated, when spermidine was removed, and the muscle tone was elevated (Fig. 7Ab). The membrane potential was $-27 \mathrm{mV}$, and the muscle underwent a contracture in the case of record B. Application of $1 \mathrm{~mm}$ spermidine caused an abrupt repolarization and the contracture was terminated (Fig. 7Ba). Action potentials composed of the initial spike followed by plateau were spontaneously generated (Fig. 7Bb). When $3 \mathrm{~mm}$ spermidine was subsequently applied, a main effect was the shortening of the plateau potential (Fig. $7 \mathrm{Bc}$ ). The membrane 
A

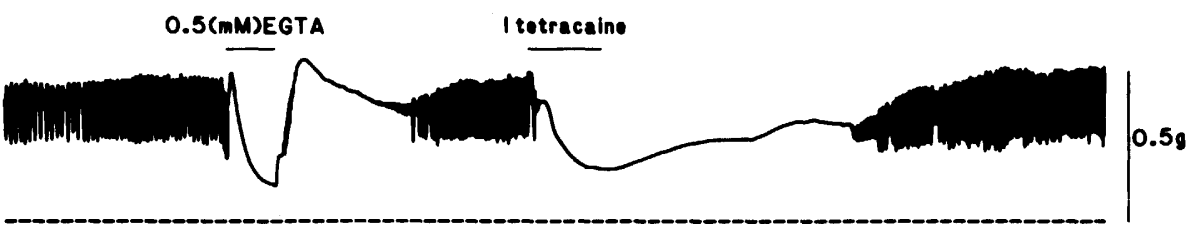

B

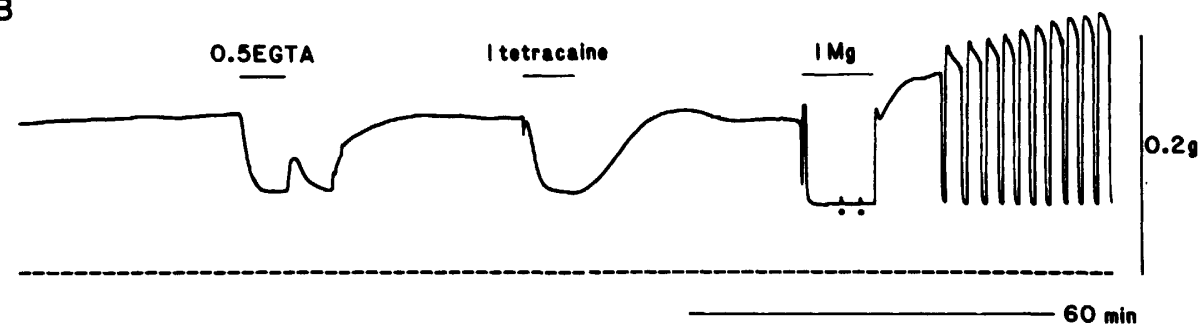

Fig. 5. Effects of Ca-depletion and $1 \mathrm{~mm}$ tetracaine on contractions in $\mathrm{Mg}$-free Krebs solution of circular muscle strips excised from postpartum rat uteri 24 (A) and $38 \mathrm{~h}$ (B) after parturition. In record B, $1 \mathrm{mM} \mathrm{Mg}$ was applied (right). Dots indicate electrical stimulation, and broken lines indicate the slack muscle tension level.

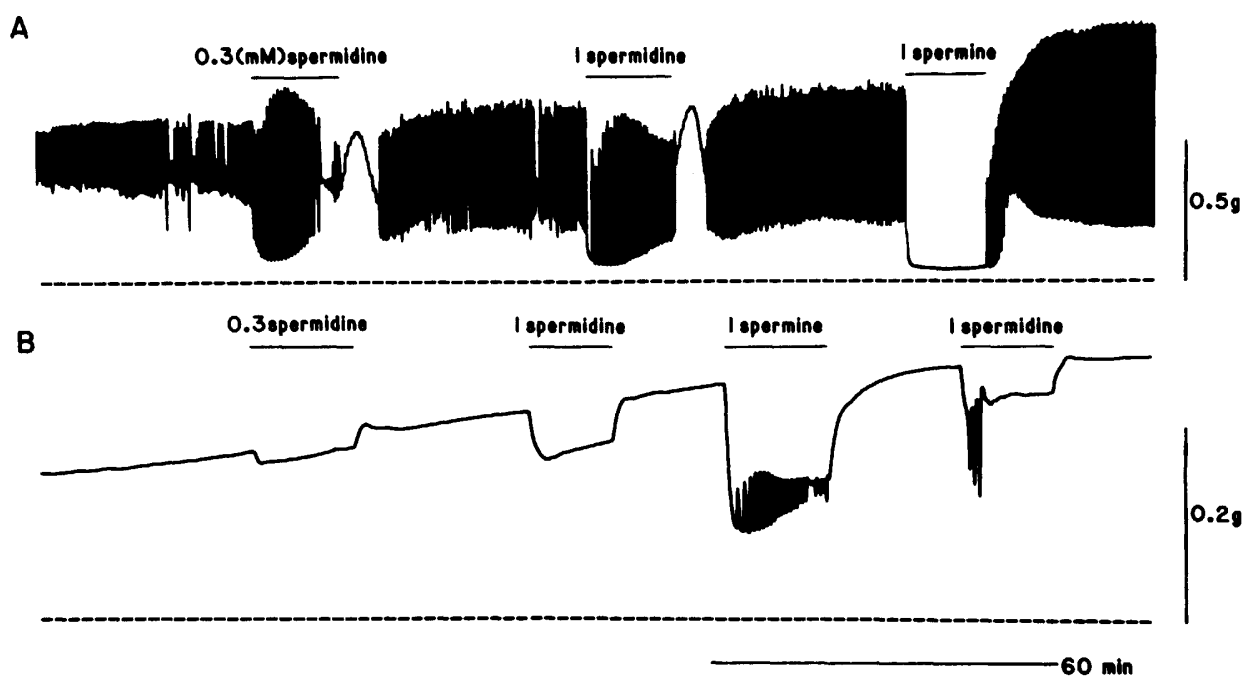

Fig. 6. Contractions of postpartum circular muscle strips in Mg-free Krebs solution illustrating effects of spermidine and spermine which were applied during the periods indicated by horizontal bars. Concentration in mм are indicated by figures. Broken lines indicate the slack muscle tension level. Circular muscle strips were excised 23.5 (A), and $32 \mathrm{~h}$ (B) after parturition, respectively. 


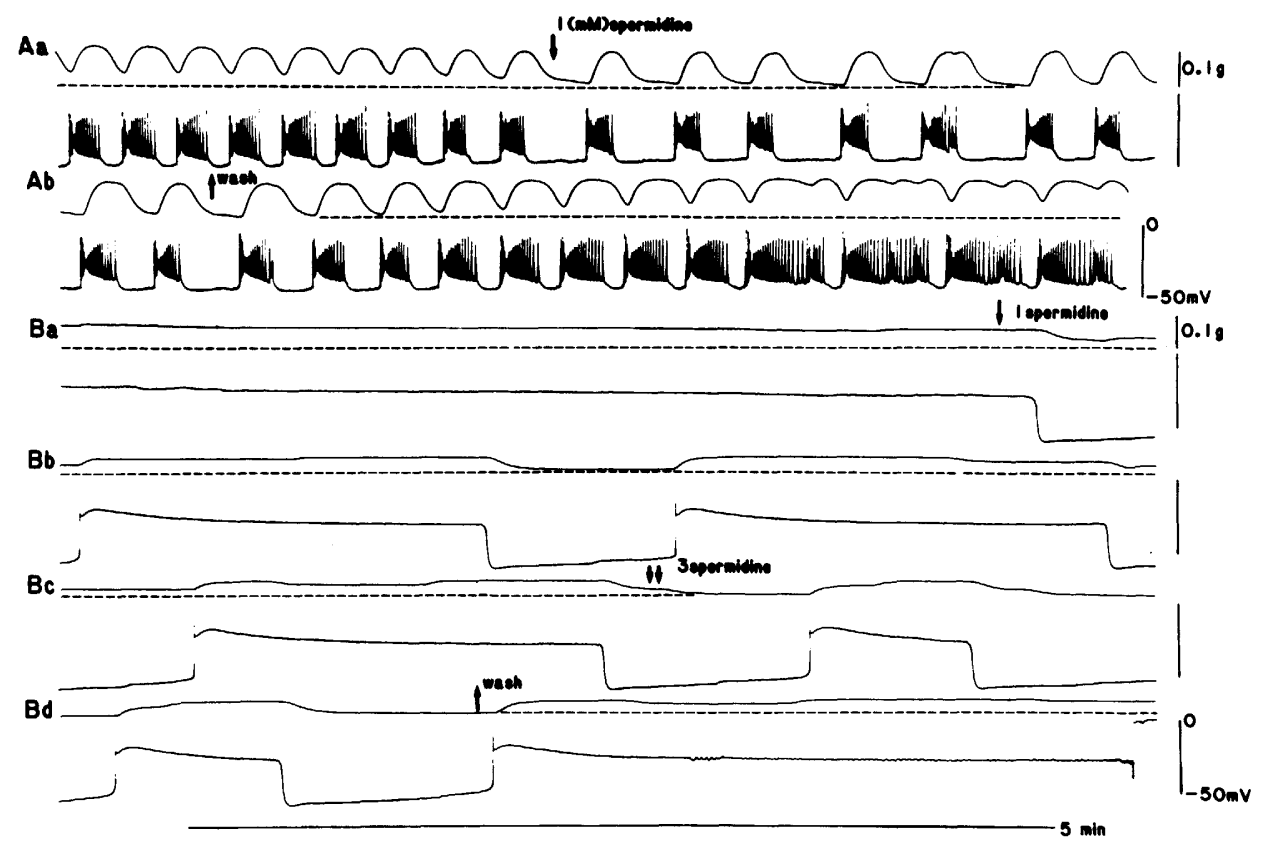

Fig. 7. Membrane activities (lower traces) of postpartum circular muscles of rat uterus illustrating effects of $1 \mathrm{~mm}$ spermidine. Contractions were simultaneously recorded (upper traces). Muscles were excised 29 (A), $39 \mathrm{~h}$ (B) after parturition and incubated with $\mathrm{Mg}$-free Krebs solution, and $1 \mathrm{~mm}$ spermidine was applied at the time indicated by arrows. In record $\mathrm{Bc}$, spermidine was further raised to $3 \mathrm{~mm}$ (arrows). $\mathrm{Ab}$ and $\mathrm{Bb}, \mathrm{Bc}, \mathrm{Bd}$ are successive records of $\mathrm{Aa}$ and $\mathrm{Ba}$, respectively.

was depolarized and a contracture was produced when spermidine was removed (Fig. 7Bd).

Application of $10^{-6} \mathrm{M}$ atropine or $10^{-6} \mathrm{M}$ phentolamine did not change the mechanical responses, indicating that cholinergic or adrenergic mechanism was not involved in such elevation of muscle tension.

A possible involvement of prostaglandins on the elevation of muscle tone is illustrated in Fig. 8. Phasic contractions were frequently generatead in the muscle strip shown in record $\mathrm{A}$. The spontaneous contraction was little affected by the application of $2 \times 10^{-5} \mathrm{M}$ aspirin, whereas $4.5 \times 10^{-5} \mathrm{M}$ indomethacin lowered the level of maximal relaxation, and the amplitude of phasic contraction was decreased. On the other hand, the frequency of phasic contraction was increased. Application of $0.2 \%$ ethanol, the amount of which was contained in the $4.5 \times 10^{-5} \mathrm{M}$ indomethacin solution, caused a slight elevation of muscle tension. The muscle relaxed, and spontaneous contractions were abolished by addition of $1 \mathrm{mM} \mathrm{Mg}$ to the Mg-free Krebs solution. The muscle underwent a contracture illustrated in record B. Aspirin $\left(2 \times 10^{-5} \mathrm{M}\right)$ slightly, and indomethacin $\left(1.5 \times 10^{-5}\right.$ and 


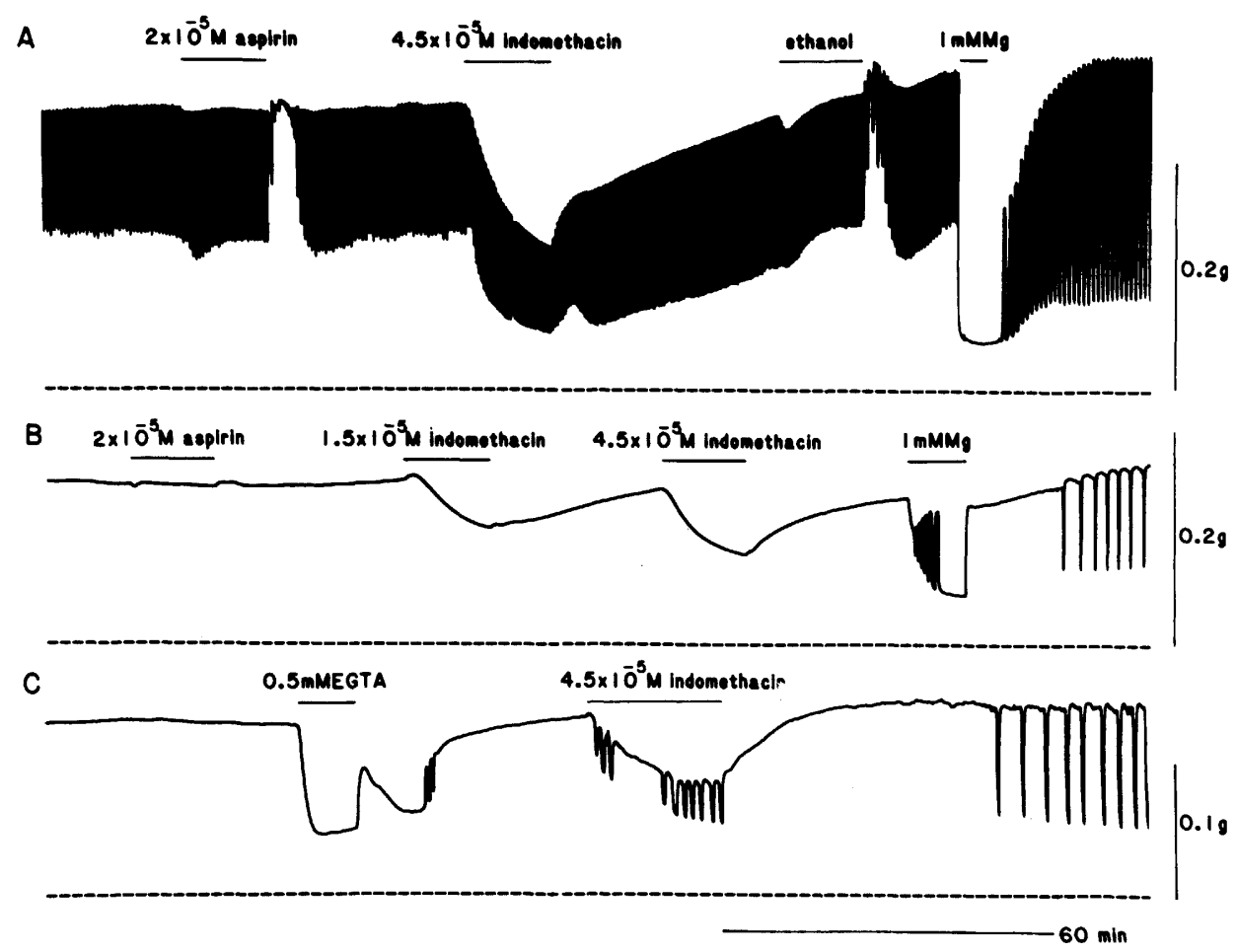

Fig. 8. Record A: effects of $2 \times 10^{-5} \mathrm{M}$ aspirin, $4.5 \times 10^{-5} \mathrm{M}$ indomethacin, $0.2 \%$ ethanol, and $1 \mathrm{~mm} \mathrm{Mg}$ added to $\mathrm{Mg}$-free Krebs solution on mechanical activity of the circular muscle strip excised $21 \mathrm{~h}$ after parturition. Record B: effects of $2 \times 10^{-5} \mathrm{M}$ aspirin, $1.5 \times 10^{-5}$ and $4.5 \times 10^{-5} \mathrm{M}$ indomethacin, and $1 \mathrm{mM} \mathrm{Mg}$ on the circular muscle strip excised $35 \mathrm{~h}$ after parturition. Record $\mathrm{C}$ : effects of $\mathrm{Ca}$ depletion and $4.5 \times 10^{-5} \mathrm{M}$ indomethacin. Circular muscle strip was obtained $40 \mathrm{~h}$ after parturition, and exposed to $\mathrm{Mg}$-free $\mathrm{Krebs}$ solution. Broken lines indicate slack muscle tension level.

$\left.4.5 \times 10^{-5} \mathrm{M}\right)$ remarkably depressed the muscle tone. $\mathrm{Mg}(1 \mathrm{~mm})$ caused a relaxation of the muscle, and spontaneous phasic contractions were generated. In the case of record $\mathrm{C}$, the muscle tension was lowered, and phasic contractions were generated by $4.5 \times 10^{-5} \mathrm{M}$ indomethacin (right), and the level of maximal relaxation was nearly the same as that caused by omission of external Ca (left).

Effects of indomethacin on the membrane activity are shown in Fig. 9. The membrane potential was $-35 \mathrm{mV}$, and spike potentials were continuously generated in $\mathrm{Mg}$-free $\mathrm{Krebs}$ solution, and accordingly the muscle underwent a tetanic contracture (Fig. 9a). When $4.5 \times 10^{-5} \mathrm{M}$ indomethacin was applied, the membrane was once repolarized, and then an action potential exhibiting a long plateau was generated (Fig. 9a, b). The duration of action potential became progressively shorter in the presenc $:$ of indomethacin, and the amplitude of the spike potential 


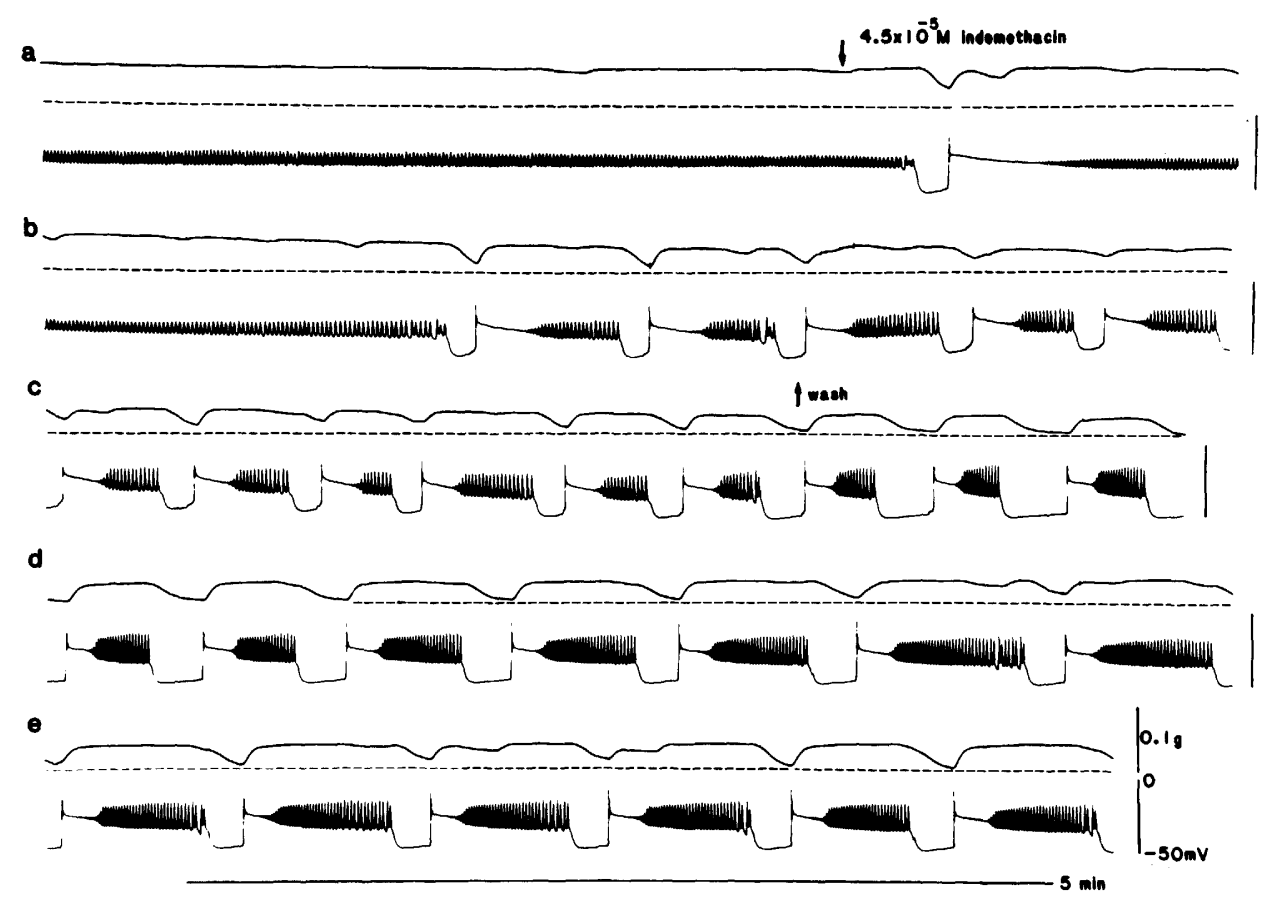

Fig. 9. Membrane activities (lower traces) of postpartum circular muscle of rat uterus illustrating effects of $4.5 \times 10^{-5} \mathrm{M}$ indomethacin. Contractions were simultaneously recorded (upper traces). Muscle was excised $39 \mathrm{~h}$ after parturition and incubated with $\mathrm{Mg}$-free Krebs solution, and indomethacin was applied during the time indicated by arrows.

generated on the plateau became larger. Phasic contractions were generated in a one-to-one manner accompanying the action potential. When indomethacin was removed (Fig. 9c), the plateau potential became gradually elongated (Fig. 9d, e).

Intracellular membrane activities of the longitudinal muscles taken $20-60 \mathrm{~h}$ after parturition are illustrated in Fig. 10. In either case, the membrane potential was about $-50 \mathrm{mV}$ in the $\mathrm{Mg}$-free $\mathrm{Krebs}$ solution, and bursts of spike potential were spontaneously generated. In the preparation taken $20 \mathrm{~h}$ after parturition, spike potentials were the predominant component (Fig. 10A). Phasic contractions arose from a well-defined baseline tension. The amplitude of spike potential was slightly larger in the presence of $1.2 \mathrm{~mm} \mathrm{Mg}$, and the duration of bursts became slightly shorter. The amplitude of accompanying contraction was slightly diminished. In the preparations taken a longer period after parturition (Fig. 10B, C), the slow potential became pronounced. The membrane was hyperpolarized by $2 \mathrm{mV}$ in the presence of $1.2 \mathrm{~mm} \mathrm{Mg}$, and spontaneous activity was suppressed. Burst of spike potential was generated by the electrical pulse, and the amplitude of spike potential was generated by the electrical pulse, and the amplitude of spike potential was generally increased. 


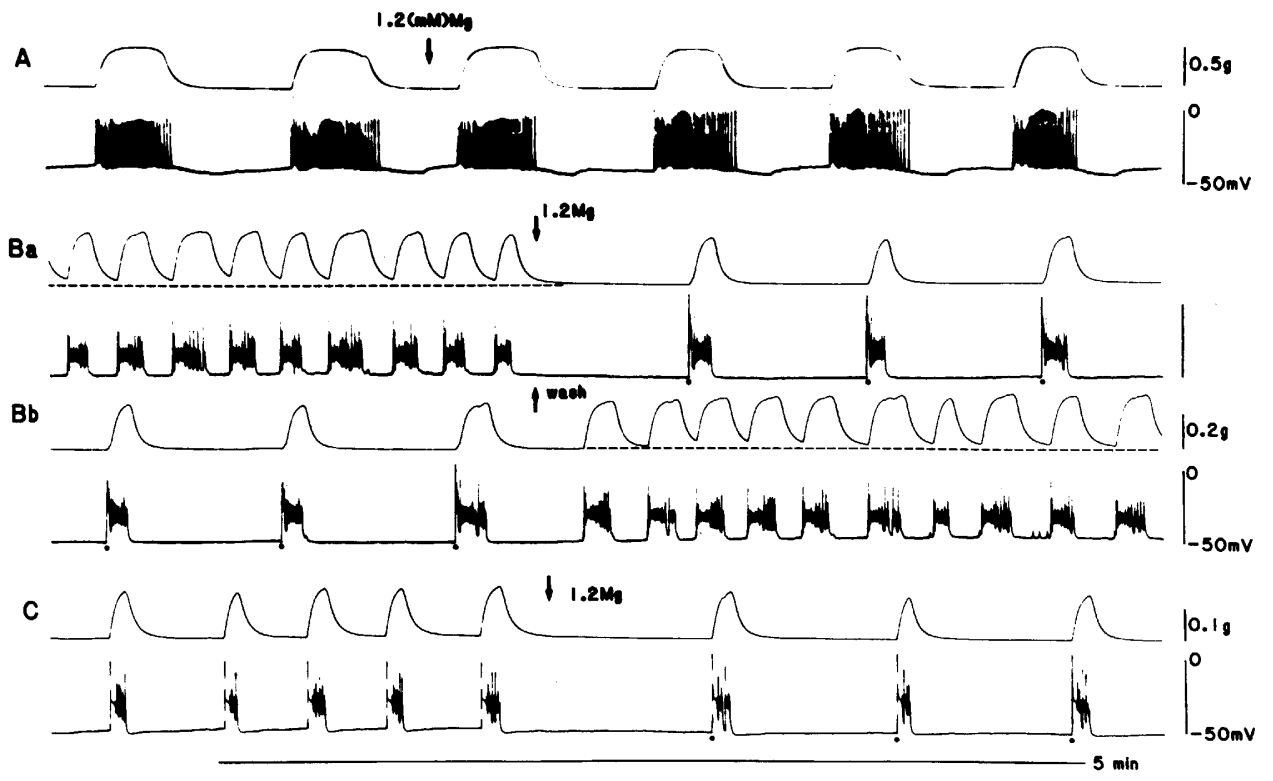

Fig. 10. Electrical activities (lower traces) of the postpartum longitudinal muscles illustrating effects of $1.2 \mathrm{~mm} \mathrm{Mg}$ (arrows). Contractions were simultaneously recorded (upper traces). Muscles were excised 20 (A), 39.5 (B), 60 (C) h after parturition, and equilibrated with $\mathrm{Mg}$-free Krebs solution. Record $\mathrm{Bb}$ shows the recovery when external $\mathrm{Mg}$ was removed. Dots indicate the electrical stimulation.

However, the accompanying contraction was smaller. The baseline muscle tension was slightly depressed by $1.2 \mathrm{~mm} \mathrm{Mg} \mathrm{(Fig.} \mathrm{10B,} \mathrm{C).}$

\section{Prepartum preparations}

The following experiments were carried out to facilitate comparison with mechanical responses in the postpartum circular muscle. Circular muscle strips excised from the prepartum rat on Day 22 of pregnancy exhibited spontaneous phasic contractions, when they were suspended under a slight stretch in $\mathrm{Mg}$-free Krebs solution. The frequency ranged between 0 and $0.3\left(\mathrm{~min}^{-1}\right)$. The muscle tone was slightly elevated and phasic contractions with greater amplitude were induced by application of $10^{-5} \mathrm{M} \mathrm{PGE}_{2}$ (Fig. 11A). The maintained muscle tone was lowered, and the generation of spontaneous phasic contractions was suppressed by the application of $\mathrm{Mg}$. Similar effects of $\mathrm{Mg}$ were caused in the $\mathrm{PGF}_{2} \alpha$-induced contractions (Fig. 11Ba). Beside the action of prostaglandin synthesis inhibitor, indomethacin is known as a Ca-antagonist for vascular smooth muscle (NORTHOVER, 1977) and myometrial muscle (ANDERSON et al., 1981). However, record $\mathrm{Bb}$ indicates that $4.5 \times 10^{-5} \mathrm{M}$ indomethacin did not depress the contractile responses induced by $\mathrm{PGF}_{2} \alpha$. 

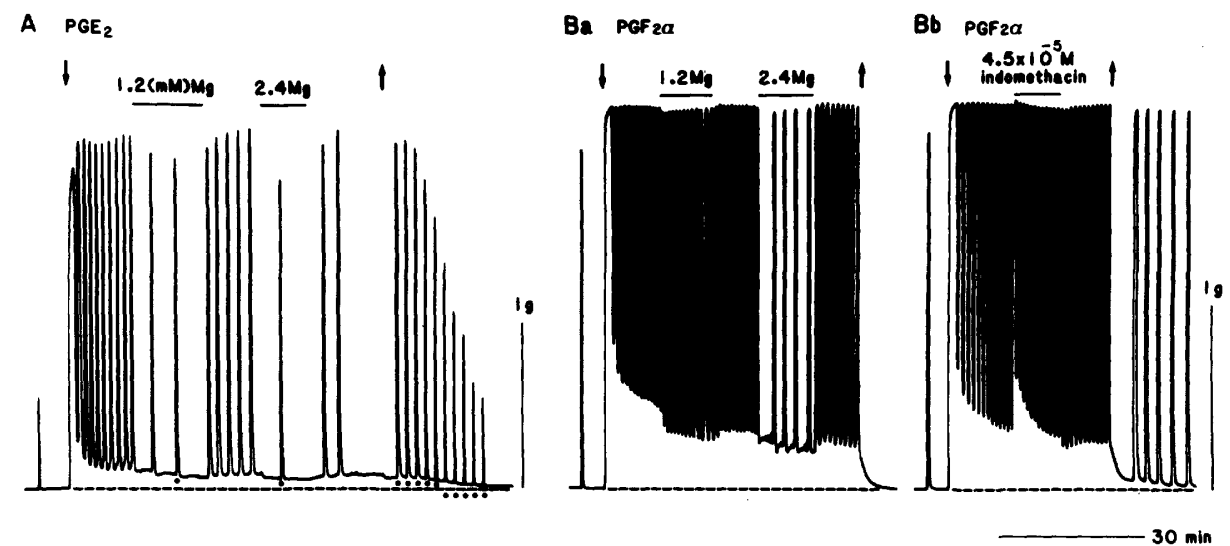

Fig. 11. Contractile responses of prepartum circular muscle strip exposed to $\mathrm{Mg}$-free Krebs solution illustrating effects of 1.2 and $2.4 \mathrm{mM} \mathrm{Mg}(\mathrm{A}, \mathrm{Ba})$, and $4.5 \times 10^{-5} \mathrm{M}$ indomethacin $(\mathrm{Bb})$ during the application (arrows) of $10^{-5} \mathrm{M} \mathrm{PGE}_{2}(\mathrm{~A})$ and $\mathrm{PGF}_{2} \alpha$ (B). Day 22 of pregnancy. Records A and B were on muscle strips taken from different animals. Dots indicate the electrical stimulation.

\section{DISCUSSION}

This study mainly describes the postpartum changes in mechanical responses of circular myometrium of rat. The changes observed in the $\mathrm{Mg}$-free $\mathrm{Krebs}$ solution are collectively summarized so that a sequence of events is an elevation of muscle tone accompanied with frequent phasic contractions starting on the first postpartum day, followed by a sustained contracture about $30 \mathrm{~h}$ after the parturition. Because $\mathrm{Mg}$ is a natural constituent of blood serum, the tissue property in vivo is better reproduced in vitro by using the artificial saline solution containing a proper concentration of $\mathrm{Mg}$. On the other hand, contrasting features between longitudinal and circular muscles were more pronounced, when they were exposed to the $\mathrm{Mg}$ free solution (for longitudinal muscle, see Fig. 10). Thus, as several investigators have pointed out, physiological and pharmacological properties are more strongly changed by hormonal condition in the circular muscle than in the longitudinal muscle (Osa and FuJino, 1978; Anderson et al., 1981; KaWArabayashi and Marshall, 1981; KishiKaWA, 1981; BengtSSON et al., 1984).

The muscle tone was elevated by raising external Ca concentration (Fig. 2B), and suppressed by Ca-depletion (Figs. 5, 8). In addition, application of $\mathrm{Mg}$, tetracaine, spermidine, and spermine, all of which are considered to be Ca-antagonists (Feinstein, 1965; Hashimoto et al., 1973; Altura and Altura, 1981; Chideckel et al., 1985; Maruta et al., 1985b; Osa and Maruta, 1986; Maruta and Osa, 1987), eliminated the contracture (Figs. 1, 5,6). Therefore, Ca is likely influxed into the cell interior from outside the membrane, when the muscle tone is high.

The contracture was depressed in low $\mathrm{K}$ solution (Fig. 3), indicating a 
membrane depolarization responsible for the above mechanical responses in the postpartum circular myometrium. The depolarization was in fact proved by microelectrode studies (Figs. 4, 7, 9). Mg and spermidine were shown to repolarize the membrane (Figs. 4, 7). Thence, the depolarization could be directly due to an increase in Ca permeability. A depolarization due to the increase in Ca permeability has been reported for the carbachol respone in intestinal smooth muscle of guineapig (Bolton and Kitamura, 1983). An increase in Na permeability is also a probable causative candidate for the membrane depolarization. It has been reported that the myometria of mouse and rat are not hyperpolarized, but, instead, depolarized, and undergo a contracture in low Na solution (OsA, 1971; MASAHASHI and Tomita, 1983). In the present study the depolarized membrane of the postpartum circular muscle was not hyperpolarized by lowering the external $\mathrm{Na}$ concentration (unpublished observation). Since the role of external $\mathrm{Na}$ on the membrane potential of uterine muscle is not yet fully understood, a conclusion concerning $\mathrm{Na}$ permeability is reserved.

The contracture was suppressed, and the membrane was repolarized by indomethacin (Figs. 8, 9). High concentration of indomethacin was required to produce the above effects, for which conclusions become controversial. Indomethacin is, on the one hand, a Ca-antagonist (NORTHOVER, 1977) and thus it is not strange that indomethacin suppressed the contracture; however, the same concentration of indomethacin $\left(4.5 \times 10^{-5} \mathrm{M}\right)$ caused only a slight effect on the contractile response induced by $\mathrm{PGF}_{2} \alpha$ in the prepartum circular myometrium (Fig. 11). Resistance of myometrial muscles in vitro to indomethacin has also been reported (ANDERSON et al., 1981). The slow time course of depression of the contracture (Fig. 8), taken together with the above arguments, favors a view that a main effect of indomethacin in the present cases was an inhibition of cyclooxygenase activity. But this view is not compatible with the minor effects of aspirin (Fig. 8). Furthermore, provided that endogenous prostaglandins were the leading cause for the contracture, an excessive production should be assumed in postpartum circular myometrium, because $\mathrm{PGE}_{2}$ and $\mathrm{PGF}_{2} \alpha$ up to $10^{-5} \mathrm{M}$ was not sufficient to produce a contracture in the prepartum circular myometrium (Fig. 11). For the above reasons, it is speculated at this moment that the synthesis of prostaglandins, probably other than $\mathrm{PGE}_{2}$ and $\mathrm{PGF}_{2} \alpha$, was raised in postpartum circular muscle tissue, and/or the sensitivity of membrane to prostaglandins was enhanced.

After the parturition, myometrial cells undergo atrophy, and proteolysis and collagenolysis occur (HARKNESS and HARKNESS, 1954; WOESSNER, 1965; HENELl et al., 1983; AdAms and Frieden, 1985; Morton and GoldSPINK, 1986). These events effect a lower distensibility and a greater regression to the postpartum uterus. During the experiment reported previously (MARUTA et al., 1985a), we experienced that the freshly excised postpartum circular muscle underwent a contracture in vitro for about $3 \mathrm{~h}$ in normal (Mg-containing) Krebs solution, as seen in Fig. 1D, then phasic contraction took place. The feature was puzzling at that time, and it is now speculated that the sequence of events depended on the gradual decrease of 
prostaglandin synthesis in vitro, and so it is likely that the contracture is a physiologic status of postpartum circular myometrium in vivo. If so, the adaptive change of postpartum regression of uterine tissue may involve such a muscular contribution.

The authors express their thanks to Ono Pharmaceutical Co. for supplying prostaglandins, and to Dr. T. Kawarabayashi, Department of Gynecology, Saga Medical College, for reading the manuscript.

\section{REFERENCES}

Aвe, Y. and Tomita, T. (1968) Cable properties of smooth muscle. J. Physiol. (Lond.), 196: $87-100$.

Adams, W. C. and Frieden, E. H. (1985) Inhibition of postpartum uterine involution in the rat by relaxin. Biol. Reprod., 33: 1168-1175.

Altura, B. M. and Altura, B. T. (1981) General anesthetics and magnesium ions as $\mathrm{Ca}$ antagonists on vascular smooth muscle. In: New Perspectives on Calcium Antagonists, ed. by Weiss, G. B., American Physiological Society, Bethesda, Maryland, pp. 131-145.

Anderson, G. F., Kawarabayashi, T., and Marshall, J. M. (1981) Effect of indomethacin and aspirin on uterine activity in pregnant rats: Comparison of circular and longitudinal muscle. Biol. Reprod., 24: 359-372.

Bengtsson, B., Chow, E. M. H., and Marshall, J. M. (1984) Activity of circular muscle of rat uterus at different times in pregnancy. Am. J. Physiol., 246: C216-C223.

Bolton, T. B. and Kitamura, K. (1983) Evidence that ionic channels associated with the muscarinic receptor of smooth muscle may admit calcium. Br. J. Pharmacol., 78: 405416.

Casteels, R. and Kuriyama, H. (1965) Membrane potential and ionic content in pregnant and non-pregnant rat myometrium. J. Physiol. (Lond.), 177: 263-287.

Chideckel, E. W., Fedan, J. S., and Mike, P. (1985) Polyamines and putreanine relax respiratory tract smooth muscle in the guinea-pig. Eur. J. Pharmacol., 116: 187-190.

Feinstern, M. B. (1966) Inhibition of contraction and calcium exchangeability in rat uterus by local anesthetics. J. Pharmacol. Exp. Ther., 152: 516-524.

HARKNESS, M. L. R. and HARKNESS, R. D. (1954) The collagen content of the reproductive tract of the rat during pregnancy and lactation. J. Physiol. (Lond.), 123: 492-500.

Hashimoto, H., Unemoto, T., and Hayashi, M. (1973) Inhibitory action of spermine on the contractions of rat uterus. Am. J. Physiol., 225: 743-746.

Henell, F., Ericsson, J. L. E., and GlaumanN, H. (1983) An electron microscopic study of the post-partum involution of the rat uterus. Virchows Arch. (Cell Pathol.), 42: 271287.

Kawarabayashi, T. and Marshall, J. M. (1981) Factors influencing circular muscle activity in the pregnant rat uterus. Biol. Reprod., 24: 373-379.

KisHIKAWA, T. (1981) Alterations in the properties of the rat myometrium during gestation and postpartum. Jpn. J. Physiol., 31: 515-536.

Maruta, K., Mizoguchi, Y., and Osa, T. (1985a) Changes in action potential and $\beta$ adrenergic effects of the circular muscle of postpartum rat uterus. Jpn. J. Physiol., 35: 567-579.

Maruta, K., Mizoguchi, Y., and Osa, T. (1985b) Effects of polyamines on the mechanical 
and electrical activities of the isolated circular muscle of rat uterus. Jpn. J. Physiol., 35: 903-915.

Maruta, K. and Osa, T. (1987) Electrophysiological effects of tetracaine on the longitudinal muscle of rat uterus in various ionic environments. Jpn. J. Physiol., 37: 851-869.

Masahashi, T. and Tomita, T. (1983) The contracture produced by sodium removal in the non-pregnant rat myometrium. J. Physiol. (Lond.), 334: 351-363.

Morton, A. J. and Goldspink, D. F. (1986) Changes in protein turnover in rat uterus during pregnancy. Am. J. Physiol., 250: E114-E120.

Northover, B. J. (1977) Indomethacin-A calcium antagonist. Gen. Pharmacol., 8: 293296.

OsA, T. (1971) Effect of removing the external sodium on the electrical and mechanical activities of the pregnant mouse myometrium. Jpn. J. Physiol., 21: 607-625.

OsA; T. and Fujino, T. (1978) Electrophysiological comparison between the longitudinal and circular muscles of the rat uterus during the estrous cycle and pregnancy. Jpn. $J$. Physiol., 28: 197-209.

Osa, T. and Maruta, K. (1986) Comparative effects of $\mathrm{Mg}, \mathrm{Ca}, \mathrm{Sr}$, and verapamil on the uterine longitudinal muscle of spayed and estrogen-treated rats. Jpn. J. Physiol., 36: 871-889.

Osa, T. and Ogasawara, T. (1983) Effects of magnesium on the membrane activity and contraction of the circular muscle of rat myometrium during late pregnancy. Jpn. J. Physiol., 33: 485-495.

Puri, C. P. and Garfield, R. E. (1982) Changes in hormone levels and gap junctions in the rat uterus during pregnancy and parturition. Biol. Reprod., 27: 967-975.

Saito, Y., SaKamoto, H., Maclusky, N. J., and Naftolin, F. (1985) Gap junctions and myometrial steroid hormone receptors in pregnant and postpartum rats: A possible cellular basis for the progesterone withdrawal hypothesis. Am. J. Obstet. Gynecol., 151: 805-812.

Sakamoto, Y., Morishita, H., and Imanaga, I. (1987) The long-lasting contraction induced by transmural stimulation in the longitudinal muscle of the guinea-pig gastric corpus. Jpn. J. Physiol., 37: 621-630.

WoEsSNER, J. F. (1965) Acid hydrolases of the rat uterus in relation to pregnancy, postpartum involution and collagen breakdown. Biochem. J., 97: 855-866. 